\title{
ПРОГНОЗИРОВАНИЕ РАЗВИТИЯ ПРИКЛАДНОЙ ПСИХОЛОГИИ КАК ПРОБЛЕМА ИСТОРИКО-ПСИХОЛОГИЧЕСКИХ ИССЛЕДОВАНИЙ
}

\author{
О. Г. Носкова
}

Московский государственный университет имени М. В. Ломоносова

Аннотация: В статье рассматривается проблема прогнозирования актуальных тем прикладной психологии на основе интерпретации содержания задач представителей новых профессий, профессий будущего. Объектом изучения стали материалы книги «Атлас новых профессий» (М., 2015), подготовленные специалистами-непсихологами, наметившими перспективные сферы профессиональной деятельности в рамках 25 ключевых отраслей экономики.

Ключевые слова: прогнозирование; прикладная психология; история психологии; мир профессий; профессиональные задачи; Атлас новых профессий

\section{FORECASTING THE DEVELOPMENT OF APPLIED PSYCHOLOGY AS AN ISSUE OF HISTORICAL AND PSYCHOLOGICAL RESEARCH}

\author{
O. G. Noskova
}

\section{Lomonosov Moscow State University}

Abstract: The article deals with the issue of forecasting the current topics of applied psychology based on the interpretation of the content of the tasks faced by representatives of new professions, professions of the future. The object of study was the materials of the book "Atlas of New Professions" (Moscow, 2015), prepared by non-psychologists, who outlined promising areas of professional activity in the framework of 25 key sectors of economy.

Keywords: forecasting; applied psychology; history of psychology; world of professions; professional tasks; Atlas of new professions

Прогнозирование направлений и тематики исследований психологической науки и практики, на наш взгляд, может быть направлением историко-психологических исследований, может опираться на фундаментальные представления о генезе и функционировании науки как познавательной деятельности представителей общества как коллективного субъекта жизнедеятельности. Достижения истории науки и техники, истории психологии могут быть полезны не только для объяснения прошлых событий в области науки, но также полезны для более адекватной ориентации исследователей в настоящем и в прогнозировании перспективных тенденций ее развития. 
Данное сообщение подготовлено как дополнительное освещение ряда идей, возникших у автора в порядке дискуссии (Носкова, 2018), в ответ на материалы статьи А. Л. Журавлева, Т. А. Нестика и А. В. Юревича «Прогноз развития психологической науки и практики к 2030 г.» (Журавлев, Нестик, Юревич, 2016). Чрезвычайно сложная проблема прогнозирования будущего развития науки (психологической науки) требует, на наш взгляд, опоры на достижения и ключевые положения современного науковедения, истории техники и естествознания, истории социо-гуманитарного знания и культурологии, футурологии, которые создают междисциплинарные основы для выделения действенных факторов, порождающих новые проблемы для психологической науки. Кроме того, может оказаться полезным опыт психологии труда, психологического профессиоведения, в рамках которых психологи традиционно заняты реконструкцией знаний и умений, необходимых для выполнения субъектом труда его профессиональных задач.

Если рассматривать психологическую науку как познавательный инструмент, полезный в осуществлении актуальных задач жизнедеятельности общества - коллективного субъекта, то оказывается возможным ориентировочный прогноз научных проблем, направлений и отраслей научно-психологического знания, которые могут быть востребованы в каждом случае применительно к прогнозируемым видам профессиональной деятельности в связи с применением перспективных новых технологий, в условиях прогнозируемых социально-технических и культурных нововведений.

Попробуем применить обозначенный способ анализа прогнозируемых новых профессиональных задач и соответствующих (потребующихся с известной вероятностью) научно-практических областей психологических знаний на примере сборника - «Атлас новых профессий» (Атлас новых профессий, 2015). Данный проект реализован при поддержке Агентства стратегических инициатив при Президенте РФ, Московской школы управления «Сколково», при участии Министерства образования и науки РФ, Министерства промышленности и торговли РФ, Министерства транспорта РФ, Worldskills Russia и др. Замысел и основное руководство проектом осуществлял Д. А. Судаков, по базовому образованию - экономист. Материал собирался в рамках так называемых «форсайт-сессий» в 2012-2014 гг., авторами описаний профессий будущего (прогноз к 2035 г.) стали около 3000 специалистов, большинство которых (за исключением Дениса Александровича Коричина, выпускника ф-та психологии МГУ имени М. В. Ломоносова) - не являлись психологами, это были специалисты в своей области: биотехнологии, медицины, сельского хозяйства, строительства, информационных технологий и т. д. И, таким образом, мы имели дело с текстом, в котором 
представлен оформленный объективно перспективный запрос общества в отношении востребованных в будущем научных знаний. И среди многообразия разных научных и научно-технических областей - тем интересней и убедительней выглядит обращение авторов к психологии, к психологическим терминам и понятиям, или формам человеческой активности, которые традиционно изучает психологическая наука наряду с другими родственными социо-гуманитарными дисциплинами.

Психологическая интерпретация перспективных профессий будущего, представленных в данном сборнике, может быть основой для формирования прогноза востребованных в будущем направлений и тематики прикладной психологии, ее теории и практики. При этом, во-первых, историк психологии может ориентироваться на выделенные авторским коллективом 11 универсальных (надпрофессиональных) навыков (или компетенций) в структуре 186 профессий будущего (при прогнозе трансформации мира профессий в течение ближайших 20 лет) (см. табл. 1) ${ }^{1}$.

Таблица 1. Перечень «надпрофессиональных» навыков (компетенций) перспективных профессий будущего

\begin{tabular}{|c|c|c|c|}
\hline $\begin{array}{l}\text { № } \\
\text { П/ா }\end{array}$ & Надпрофессиональные навыки & $\begin{array}{l}\text { N (частота } \\
\text { встречаемости } \\
\text { признака) }\end{array}$ & $\%$ \\
\hline I & Системное мышление & 153 & 82 \\
\hline II & Межотраслевая коммуникация & 101 & 54 \\
\hline III & Управление проектами & 112 & 60 \\
\hline IV & Бережливое производство & 49 & 26 \\
\hline V & $\begin{array}{l}\text { Программирование/Робототехника/ } \\
\text { Искусственный интеллект }\end{array}$ & 112 & 60 \\
\hline VI & Клиентоориентированность & 94 & 51 \\
\hline VII & Мультиязычность и мультикультурность & 92 & 49 \\
\hline VIII & Работа с людьми & 79 & 42 \\
\hline IX & Работа в условиях неопределенности & 30 & 16 \\
\hline $\mathrm{X}$ & Навыки художественного творчества & 31 & 16 \\
\hline $\mathrm{XI}$ & Экологическое мышление & 59 & 32 \\
\hline
\end{tabular}

(Атлас новых профессий, 2015: 15).

\footnotetext{
${ }^{1}$ В последующем тексте прогнозируемые нами психологические проблемы и направления выделены курсивом.
} 
П.1 (Системное мышление) свидетельствует о важности системной методологии, как в научных исследованиях, так и в практике (проектировании техники, видов труда, в педагогике - общеобразовательной и профессиональной). Системный подход укрепился в отечественных науках, включая психологию, еще в 70-80-е гг. XX в.; системная методология не утратила своей актуальности в настоящее время и, можно надеяться, вслед за авторами «Атласа новых профессий», - будет актуальна и в будущем. Можно прогнозировать в будущем возрастание интереса практиков не только к диагностике имеющегося уровня системного мышления претендентов на новые профессии, но особенно к технологиям направленного формирования системного мышления в профессиональном обучении, возможность и эффективность которого убедительно доказана 3. А. Решетовой и ее учениками (Формирование ... , 2002). Системность мышления - ключевая характеристика успешности и надежности труда профессионалов в опасных профессиях и профессиях, использующих сложные информационные технологии, представлена в 82\% проанализированного множества новых профессий.

П.ІІ (Межотраслевая коммуникация) - этот вид навыков можно интерпретировать как продолжение и следствие п. 1. Оправдан вывод о важности системной методологии для теоретической и практико-ориентированной психологии будущего.

П. ХІ (Экологическое мышление) - можно рассматривать как частный вариант системной методологии, ибо понятие экологии - учения о среде, в которой живут люди, животные, биологические организмы разных форм, - это, по сути, учение о соотношении функционирования системных объектов и объемлющей их системы, об их различных взаимосвязях и взаимоотношениях. Можно прогнозировать актуальность в будущем сложившейся к настоящему времени экологической психологии.

П. III (Управление проектами) и п. IV (Бережливое производство) свидетельствуют о необходимости освоения представителями всех специальностей (включая и психологию) основ научного менеджмента, начиная с его классических форм, сложившихся в работах Ф. У. Тейлора и А. Файоля до «Бережливого производства» - аналога классики научного управления начала XX в. Из этого положения следует сохранение в прогнозируемом будущем актуальности и роста лидирующих позиций организационной психологии и психологии труда, психологии управления (менеджмента), разрабатывающих соответствующий круг проблем.

П.V (Программирование / Робототехника / Искусственный интеллект) данный вид навыка утверждает необходимость владения представителями перспективных профессий основами информационных технологий, робототехники, как ключевых (революционных) технологических достижений. 
Научные труды Московского гуманитарного университета 2019 № 1

Отсюда вытекает важная роль когнитивной экспериментальной психологии, когнитивной эргономики (вобравшей традиции инженерной психологии), психологии и психофизиологии восприятия (при сравнительном анализе восприятия человека и технических средств, перцептронов), психологии памяти, психологии мышления (принятия решений), психологии, психофизиологии, нейронаук в изучении и проектировании искусственного интеллекта, моделировании других ментальных и психомоторных процессов.

П. VI (Клиентоориентированность) и п. VIII (Работа с людьми) - эти навыки потребуют от профессионала использования знаний в области социальной психологии, психологии общения, восприятия человека человеком, психологии конфликтов и переговоров, развития социального и эмоционального интеллекта. Будут также востребованы, перспективны соответствующие направления в области дифференциальной психологии и тестологии, психологии развития, возрастной психологии, педагогической психологии, проблемы и методы психологии воздействия, социальной психологии, клинической психологии.

П. VII (Мультиязычность и мультикультурность) - эти характеристики субъекта труда и соответствующие профессиональные компетенции потребуют в своем развитии использование достижений этнопсихологии, психологии религии, психолингвистики, психосемантики в их теории, методах исследования и практических технологиях.

П. IX (Работа в условиях неопределенности) и п. X (Навыки художественного творчества) - данные надпрофессиональные навыки можно было бы обозначить как способности, требующие новаторства, творческого отношения к делу (которое необходимо во всех сколько-нибудь сложных профессиях, а не только в области художественного творчества). П. IX предполагает готовность работника самостоятельно планировать свою деятельность, в условиях неопределенности, а, следовательно, отсутствия готовых алгоритмов действий. От профессионала потребуется быть самостоятельным, с высоким уровнем самоконтроля и сознательной самоорганизации, саморегуляции, тайм-менеджмента, самоменеджмента, ответственности и чувства долга. На первый план при этом с необходимостью выдвигаются проблемы воспитания (морального, трудового, гражданского, эстетического) личности, формирования личности независимой, высокосознательной, способной к автономной осознанной трудовой активности. Это традиционные проблемы психологии личности, психологии педагогической, психологии воздействия. Можно добавить проблемы психологии безопасности (ибо поведение в условиях неопределенности чревато риском ошибочных действий). Можно также добавить проблемы психологии искусства (включая вопросы профессионального труда работников, создающих произведения 
искусства и проблемы потребления произведений искусства, воспитания культуры потребления).

Во-вторых, помимо перечисленных выше перспективных направлений теории и практики психологии, вытекающих из нашей интерпретации выделенных универсальных надпрофессиональных умений, можно обозначить направления и отрасли психологии, частные психологические проблемы и темы, которые нетрудно вычленить из описания конкретных «новых» профессий, профессий будущего, представленных в обсуждаемом сборнике в каждой отрасли общественной жизни. Можно в качестве примера привести состав задач двух профессий из области биотехнологии, в одной из которых успешность профессиональной деятельности работника возможна без использования обстоятельных научно-психологических знаний, а в другой, напротив, предполагается опора на специальные психологические исследования. Примером первой профессии будущего может быть биофармаколог, краткое описание состава его обязанностей выглядит следующим образом: «Специалист по проектированию новых биопрепаратов с заданными свойствами или по замене искусственно синтезированных препаратов на биопрепараты. Уже сегодня ряд важных лекарств - например, пенициллин или инсулин производится при помощи генно-модифицированных бактерий» (Атлас новых профессиц, 2015: 33). Из 11-ти надпрофессиональных навыков данного специалиста к гуманитарным наукам автор текста справедливо отнес мультиязычность и мультикультурность, которые могут быть полезны при знакомстве работника с публикациями, отражающими новейшие достижения в данной области на иностранных языках. Однако, здесь речь идет о знании иностранных языков, лишь как средства получения нужной информации специалистом, но не требуются глубокие специальные знания в области психолингвистики или психологии общения. Примером новой профессии, порождающей относительно новые проблемы психологии, может служить профессия урбаниста-эколога, также имеющая отношение к биотехнологии. Однако здесь специалисту важны надпрофессиональные навыки работы с людьми, так как люди не только загрязняют городскую среду нарушением норм и правил организационного поведения, но люди также являются и объектами воздействия среды. И специалисту важно владеть соответствующими знаниями в области профессиональной гигиены, медицины труда, а также уметь использовать сведения о людях, их потребностях и привычках при проектировании новых городов на основе экологических биотехнологий, используемых в области строительства, энергетики и контроле загрязнения среды. «Высокотехнологичные «зеленые города» проектируют и строят в Малайзии, Китае, Арабских Эмиратах, Индии, Южной Корее и странах Европы» (там же). 
Научные труды Московского гуманитарного университета 2019 № 1

Формирование экологического мышления и осознанного экологического поведения у представителей городского населения разных культурных и возрастных групп - одно из сложившихся и перспективных направлений экологической психологии, которое, несомненно, останется актуальным и через 20 лет, ибо интенсивность загрязнения планеты (особенно в крупных городах, мегаполисах) возрастает.

Далее может быть проведен психологический анализ намеченного состава основных задач специалистов новых профессий и экспертная оценка несколькими независимыми экспертами тематического содержания названия профессии, а также предметного содержания деятельности профессионала и требуемых для успешности деятельности надпрофессиональных навыков (универсальных компетенций), их относительно частой встречаемости в массиве обследованных новых профессий. Эти материалы могут, на наш взгляд, быть использованы как один из источников построения прогноза будущее востребованнысти знаний научной психологии в будущем.

Понятно, что наши материалы не могут рассматриваться как результаты завершенного исследования, которое могло бы дать читателю репрезентативную, относительно полную картину прогноза представленности прикладных научно-психологических знаний к 2035 г. Однако, как нам представляется, в итоге проведенного анализа, можно считать доказанными применимость самого подхода, возможность и оправданность использования материалов прогнозирования перспектив обновления техники и технологий, описаний стратегически важных для общественной жизни трансформаций мира профессий - в деле составления картины будущего развития психологической науки, ее практики и теории.

\section{СПИСОК ЛИТЕРАТУРЫ}

Атлас новых профессий (2015) / ред. Д. Варламова. М. : Агентство стратегических инициатив, «Сколково» ; Моск. школа управления. 288 с.

Журавлев, А. Л., Нестик, Т. А., Юревич, А. В. (2016) Прогноз развития психологической науки и практики к 2030 г. // Психологический журнал. T. 37. № 5. С. 55-74.

Носкова, О. Г. (2018) Будущее психологической науки и практики с позиции истории психологии и науковедения // Психологический журнал. Т. 39. № 4. C. 122-125. DOI: 10.31857/S020595920000077-0

Формирование системного мышления в обучении (2002) / под ред. 3. А. Решетовой. М. : ЮНИТИ-ДАНА. 344 с.

Дата поступления: 15.01.2019 г. 
Носкова Ольга Геннадьевна - доктор психологических наук, професcop, профессор кафедры психологии труда и инженерной психологии факультета психологии Московского государственного университета имени М. В. Ломоносова. Адрес: 125009, Россия, г. Москва, ул. Моховая, д. 11, стр. 9. Тел.: +7 (903) 274-17-83. Эл. адрес: nog4813@mail.ru

Noskova Olga Gennadyevna, Doctor of Psychology, Professor, Professor, Department of Psychology of Labor and Engineering Psychology, Faculty of Psychology, Lomonosov Moscow State University. Postal address: 11, Bldg. 9, Mokhovaya St., Moscow, Russian Federation, 125009. Tel.: +7 (903) 274-17-83. E-mail: nog4813@mail.ru

\section{Для цитирования:}

Носкова О. Г. Прогнозирование развития прикладной психологии как проблема историко-психологических исследований [Электронный ресурс] // Научные труды Московского гуманитарного университета. 2019. № 1. URL: http://journals.mosgu.ru/trudy/ article/view/938 (дата обращения: дд.мм.гг.). DOI: 10.17805/trudy.2019.1.11 